\title{
Influence of Trait-Anxiety on Inhibition Function: Evidence from ERP Studies
}

\author{
Yue-jia Luo, Ruolei Gu and Yu-xia Huang \\ State Key Laboratory of Cognitive Neuroscience and Learning, \\ Beijing Normal University
}

China

\section{Introduction}

\subsection{Influence of anxiety on Inhibition function: Emotional processing}

Many researchers have reported that anxiety patients are more sensitive to emotional stimuli, particularly negative stimuli. This phenomenon is suggested to be linked with highanxiety people's inhibition dysfunction when facing emotional stimuli (Barkley, 1997; Enright \& Beech, 1993). Supporting this idea, there has been an increasing amount of literature addressing the inhibition mechanisms in high-anxiety individuals. For instance, many previous studies indicated that high-anxiety people may find it harder than low-anxiety people to inhibit the processing of emotional stimuli, especially the threatening contents (Derakshan, Ansari, Hansard, Shoker, \& Eysenck, 2009; Mogg \& Bradley, 1998; Mogg, Bradley, Williams, \& Mathews, 1993). Yee \& Vaughan (1996) suggest that anxiety disorders may associate with inhibition failure, and the inhibition processes in the executive function affects individuals as early as during childhood (see also Livesley, Jang, \& Vernon, 1998).

In this study, we attempted to compare the difference in inhibition function between high and low trait-anxiety individuals during emotional processing. With reference to previous studies, we adopted the oddball paradigm involving novel stimuli (i.e., inserting an additional stimulus as the interference when subjects were performing the discrimination task) (Fichtenholtz et al., 2004). In order to complete cognition tasks, subjects should inhibit the emotional distracting stimuli. This paradigm is suitable to investigate inhibition mechanisms of emotional interferences and has been widely used in studies on attention and emotion (Yamasaki, LaBar, \& McCarthy, 2002).

A total of 210 undergraduate students completed the Chinese version of Spielberger's trait anxiety (Shek, 1993) which has good validity and reliability evidenced by a large sample survey (Spielberger, Gorsuch, Lushene, Vagg, \& Jacobs, 1983; Zheng et al., 1993). The average trait-anxiety score from participants investigated in the current study was $40.1 \pm$ 10.1. Participants whose trait-anxiety scores were over 45 were grouped as high-trait anxiety (HTA) individuals, whereas the low-trait anxiety (LTA) group comprised subjects whose scores were equal or less than 35 .

It is indicated that the response bias may influence the reliability of psychological assessment and measurement, especially in the self-report measurement. In order to decrease the bias from the socially desirable responding, we asked the participants to complete the Marlowe-Crowne Social Desirability Scale (MCSD) (Crowne \& Marlowe, 1960; 
Wang, Wang, \& Ma, 1999). The mean MCSD score from the sample of university students was $15.5 \pm 4.4$ (Wang et al., 1999). In the current study the average MCSD score was $15.6 \pm$ 4.4. Participants whose scores were over 20 were excluded from the EEG data acquisition.

Finally, the study comprised 28 right-handed subjects without neurological or mental illness, ranging in age from 18 to 25 years (mean age: 22 years). In this sample, 14 participants were assigned to the HTA group (6 men and 8 women) and 14 participants to the LTA group (4 men and 10 women). The trait-anxiety score of the HTA group was significantly higher than that of the LTA group (51.6 vs. $27.9, p<0.001$ ). The difference in MCSD scores between the two groups was not salient (13.9 versus 12.1, $p>0.05$ ). Participants signed the informed consent before the experiment, and received remuneration on completion of the study.

The formal task contained three types of stimuli: standard ones, target ones, and novel ones. Standard stimuli and target stimuli were geometric figures (round, square, or triangle). Target stimuli were larger than standard figures by $5 \%$. There were 1440 standard stimuli and 180 target stimuli. Novel stimuli were 180 color pictures selected from the Chinese Affective Picture System (CAPS) (Bai, Ma, Huang, \& Luo, 2005), including 60 positive pictures (e.g., delicious food), 60 neutral pictures (e.g., household appliances), and 60 negative pictures (e.g., scene of a car accident). The emotional valence in positive and negative pictures was significantly different from that in the case of neutral pictures $(7.42$ versus $5.11, p<0.01 ; 2.40$ versus 5.11, $p<0.01$ ); also, positive and negative pictures caused significantly higher arousal of emotion than neutral pictures (5.89 vs. $3.43, p<0.01 ; 5.84$ versus $3.43, p<0.01$ ). The valence extremity and the arousal level were matched across positive and negative pictures. The rating scores of pictures were from a body of Chinese university students who had similar backgrounds with participants of the current study. Subjects' eyes were $1 \mathrm{~m}$ away from the screen. The height of the pictures was $8.0 \mathrm{~cm}$ and length was $10.6 \mathrm{~cm}$. The visual angle of the pictures was $6.07^{\circ} \times 4.58^{\circ}$.

Prior to the experiment, subjects were asked to complete the STAI again. The trait-anxiety scores of the HTA and LTA groups were 53.4 and 29.4, respectively. There was no significant difference in trait-anxiety level between the two tests. The experimental paradigm was the oddball task with three types of stimuli, of which, $75 \%$ were standard stimuli; $12.5 \%$, target stimuli; and $12.5 \%$ novel stimuli. The entire experiment consisted of 6 blocks including 240 standard stimuli, 30 target stimuli, and 30 novel stimuli (10 pieces of positive, neutral, and negative pictures each) in each block. The trials were presented in a random order within each block. Among them, the target stimuli and standard stimuli were geometric figures with subtle differences in size, and each novel stimulus was only presented once during the entire experiment. Standard stimuli were presented for $500 \mathrm{~ms}$, the target and the novel stimuli were presented for $750 \mathrm{~ms}$ at the center of the screen. The interval between them randomly ranged from 900 to $1000 \mathrm{~ms}$. Subjects were required to focus on the subtle size difference between the standard and target stimuli and press the space bar immediately after seeing the target stimuli. The response hands and the order of blocks were counterbalanced between subjects. There was a short break between each block. We instructed the subjects to concentrate on the discrimination task and try their best to inhibit the influence of novel stimuli.

The electroencephalogram (EEG) was recorded during the task. Each participant's data were aggregated based on the type of novel stimuli (positive, neutral, or negative). Thus, three kinds of averages were generated from each participant. We measured the baseline-peak 
amplitudes and the peak latencies of N1 (time window: 90-150 ms), P2 (time window: 150$200 \mathrm{~ms}$ ), N2 (time window: 200-280 ms), and P3 component (time window: 280-430 ms). A repeated-measure ANOVA was used with anxiety level (high/low), emotion property (positive/neutral/negative), laterality (left/right/midline), and anteriority (frontal/frontocentral/central/centro-parietal) as statistical factors. The Greenhouse-Geisser epsilon correction was applied to adjust the degrees of freedom of the F-ratios when necessary.

The analysis on the reaction time was conducted on the trials with correct responses. The reaction time of the HTA group and the LTA group was $527.37 \pm 39.13 \mathrm{~ms}$ and $534.55 \pm 42.89$ $\mathrm{ms}$, respectively. The difference between the groups was not significant $(t=7.17, p>0.05)$. The mean response accuracies of both groups were about $70 \%$. We compared the ERP data induced by negative and positive pictures, with the neutral condition as the control group. Three types of emotional pictures all evoked N1, P2, N2, and P3 components in the scalp.

The only significant effect of the N1 amplitude was found on the anteriority factor $(\mathrm{F}(3,78)$ $=58.48, p<0.01)$. N1 amplitudes were relatively higher in the anterior scalp. ANOVA conducted on $\mathrm{P} 2$ amplitudes revealed significant main effects of the emotion property factor $(\mathrm{F}(2,52)=16.44, p<0.01)$.

P2 amplitudes evoked by negative pictures were relatively lower than those evoked by other types of stimuli. P2 latencies also showed main effects for emotion property $(\mathrm{F}(2,52)=$ $7.83, p<0.01)$. Negative stimuli elicited relatively shorter P2 latencies. With respect to N2 amplitudes, the main effect for emotion property was significant $(F(2,52)=23.72, p<0.01)$.

$\mathrm{N} 2$ amplitudes were highest when induced by negative pictures, and those induced by neutral pictures were the lowest. N2 amplitudes were also found to peak over the midline of the scalp, and the amplitudes over the right hemisphere were greater than those over the left hemisphere $(\mathrm{F}(2,52)=14.39, p<0.01)$. The anxiety level significantly affected N2 latencies $(\mathrm{F}(1,26)=5.07, p<0.05)$, which was shorter in HTA individuals. There was a main effect of $\mathrm{N} 2$ latencies for emotion property as well $(\mathrm{F}(2,52)=5.59, p<0.01)$. N2 latencies were the shortest under the negative condition and longest under the neutral condition.

A significant main effect of $\mathrm{P} 3$ amplitudes was observed on emotion property $(\mathrm{F}(2,52)=20.08$, $p<0.01)$. P3 amplitudes were the largest under the neutral condition and smallest under the negative condition. Laterality of P3 amplitudes was similar to the results of the N2 component, which revealed that P3 amplitudes were largest over the midline of the scalp, and the right hemispheric amplitudes were larger than the left hemispheric amplitudes $(\mathrm{F}(2,52)=11.80, p<$ $0.01)$. There were significant interactions between the anxiety level and the emotion property $(\mathrm{F}(2,52)=10.31, p<0.01)$. Further, simple effect analysis showed that there was a difference in P3 amplitudes between the HTA group and the LTA group. P3 amplitudes induced by positive stimuli in the HTA group were significantly smaller than those in the LTA group. Another interaction effect of $\mathrm{P} 3$ amplitude was between the laterality and the anteriority factor $(\mathrm{F}(6,156)=26.70, p<0.01)$. P3 amplitudes peaked at $\mathrm{CPz}$ site. In conclusion, the arrangement rules of the $\mathrm{P} 3$ component elicited by the three types of pictures were different between the HTA and LTA groups. The difference between the groups largely embodied the differentiation of P3 amplitudes evoked by positive stimuli.

In this study, we found that in both groups, the P3 amplitude induced by negative pictures was smaller than that induced by neutral pictures. This result implies that subjects inhibited the influence of negative stimuli. In the LTA group, the P3 amplitude showed no significant difference between the positive and the neutral conditions, while the P3 amplitude induced by positive pictures in the HTA group was smaller than that induced by neutral pictures. 
These results indicate that high-anxiety individuals use the same inhibition strategy towards positive and negative pictures. In other words, they show a tendency of excessive inhibition regardless of the emotional valences of the stimuli.

Some researchers emphasize the importance of endogenous components, such as N2-P3-P4, in the studies on inhibition function (Ilan \& Polich, 1999). The P3 component is considered to be the index of inhibition to task-irrelevant information. Falkenstein, Hoormann, \& Hohnsbein (1999) proposed that P3 marks the completion of the entire inhibition process. Moser et al. (2006) found that the LPP amplitude was significantly decreased when subjects were required to actively inhibit the influence of negative pictures. Fallgatter, Bartsch, \& Herrmann (2002) also suggested that P3 may associate with high-load inhibition.

This study used an improved oddball paradigm, in which subjects would more likely pay attention to novel stimuli that interfered with the discrimination of standard and target stimuli. Subjects have to actively inhibit the interference in order to successfully complete the discrimination tasks. This anti-interference effort was manifested by significantly decreased P3 amplitudes in both high-anxiety and low-anxiety individuals under the negative condition compared to those under the neutral condition. The major difference between those two groups was that they showed different degrees of inhibition to positive information. Compared to the neutral condition, P3 amplitudes elicited by positive pictures were decreased in high-anxiety individuals, while there was no significant difference among the low-anxiety individuals. The results indicate that low-anxiety individuals selectively inhibit negative stimuli but do not make much effort to inhibit the positive stimuli since they are not so intrusive. In contrast, high-anxiety individuals feel that positive stimuli are very disturbing also, so they treat the two types of stimuli in the same way and show an over-inhibited tendency. Behavior inhibition model postulated by McNaughton \& Gray (2000) suggests that BAS would be activated when one perceives some reward or beneficial information, while BIS would be activated when people meet conflicting stimuli (including non-reward stimuli, punishment stimuli, and novel stimuli which are irrelevant to the ongoing task). The activation of BIS would increase the level of response inhibition as well as enhance the attentional vigilance. This study provides evidences of the abnormal activation of BIS in high-anxiety individuals.

Many previous studies (Derakshan et al., 2009; Mogg \& Bradley, 1998; Mogg et al., 1993) indicate that high-anxiety individuals may find it harder than low-anxiety individuals to inhibit the processing of emotional stimuli, especially threatening contents. However, highanxiety participants in this study did not show differences in P3 amplitudes, unlike lowanxiety participants, when they were shown the negative pictures. One possible reason is that the high-anxiety people might try it harder to resist the interference from emotional stimuli because of their inhibition tendency. That may compensate their deficiency in inhibition function to some extent. The reaction time didn't show any significant difference between the high and low-anxiety groups, which could result from the same compensation effect. We suspect that when the task is not too difficult, high-anxiety people, to some degree, can balance the stimulus driven attentional system and the top-down, goal-driven attentional system (Critchley, Mathias, \& Dolan, 2001; Eysenck, Derakshan, Santos, \& Calvo, 2007). These efforts may help them resist the disruption of task-irrelevant negative stimuli. Meanwhile, the inhibition tendency might result in excessive inhibition of positive stimuli, which is evidenced in this study. This suggestion is speculative and should await future investigations. 
In this study, the inhibition function localized by source analysis reveal that most of the P3 variations were attributed to the activation of the right centro-posterior cingulate cortex (PCC). As proposed by McNaughton (1997, 2006), anxiety might result from hyper-activity of the septohippocampal system which includes hippocampus, entorhinal cortex and PCC. The PCC contributes to a dynamic re-mapping of the physical state of the organism in response to current behavioral and environmental contexts (Critchley et al., 2001). In Li et al.'s study (2005), abstinent cocaine users showed an inverse correlation between the craving rating and the activity in the right PCC when they were presented stressful images. The results indicate that the PCC might exert a regulatory role in inhibiting craving responses. The PCC may be the brain region where the behavioral inhibition system executes the conflict supervision and response inhibition function.

\section{Influence of anxiety on inhibition function: Decision making}

In economic models, risk is defined as a cost that a decision-maker compares with the expected value so as to make a choice (Rushworth \& Behrens, 2008). In the experimental psychological branch of decision-making research, the participants are often provided two options for them to choose. Between them, the option that is linked with higher level of risk is called a risky choice, while the other is called a risk-avoidant choice, or 'safe' choice (i.e. Goyer, Woldorff, \& Huettel, 2008). Risk-avoidance tendency, therefore, refers to the preference of consistently picking the risk-avoidant option. Higher levels of trait anxiety are positively correlated with risk-avoidance in decision-making studies. That is, high-anxiety people are more prone to avoid risky choices when finishing decision-making tasks, compared to low-anxiety people (Eisenberg, Baron, \& Seligman, 1998; Maner et al., 2007; Maner \& Schmidt, 2006; Miu, Heilman, \& Houser, 2008; Shepperd, Grace, Cole, \& Klein, 2005; Wray \& Stone, 2005). The reason for this phenomenon is still under debate.

The abnormality of inhibition function is suggested to be linked with higher levels of anxiety. Nigg (2000, 2001) distinguishes between two kinds of inhibition function: behavioral inhibition and motivational inhibition. The first type is related to response inhibition, while the second type is related to personality traits such as anxiety levels. Highanxiety subjects find it harder to inhibit the recall of threatening memory, compared to nonthreatening information (Reidy \& Richards, 1997). In addition, high-anxiety people are more likely to overreact to negative stimuli, indicating the dysfunction of inhibition control (Etkin, Klemenhagen, \& Dudmen, 2004; Li, Wang, Poltakoff, \& Luo, 2007). Bar-Haim, Lamy, \& Glickman (2005) point out that the attentional bias (paying more attention to negative valence emotional stimuli) in high-anxiety participants reflects difficulty in disengaging attention from the stimuli once it has been attended, rather than speeded engagement of attention. Some researchers highlight the inability to inhibit fear-generating processing as the reason of attentional bias (Mayer \& Merckelbach, 1999). Consistent with this idea, the level of trait anxiety is correlated with activation level of lateral prefrontal cortex (Bishop, 2009; Bishop, Duncan, \& Lawrence, 2004), which is also linked with inhibition control (Dias, Robbins, \& Roberts, 1997).

The inhibition function is suggested to play an important role in the process of decision making, since deliberate decision (the decisions marked by consideration of available behavioral choices as well as their consequences) need people to inhibit inappropriate 
behaviors (Sakagami, Pan, \& Uttl, 2006). In agreement with this viewpoint, recent studies reveal that ADHD children's dysfunction in inhibition control might have something to do with their decision-making deficit (see Geurts, van der Oord, \& Crone, 2006). Similar results have been founded in individuals with alcoholism (Noel, Bechara, Dan, Hanak, \& Verbanck, 2007). Patients with lesions in the ventral lateral prefrontal cortex (VLPFC), a region that is linked with uncertain or risky decision making (Goel \& Dolan, 2000; McClure, Laibson, Loewenstein, \& Cohen, 2004), also show difficulties on behavioral inhibition measures (Aron, Fletcher, Bullmore, Sahakian, \& Robbins, 2003), implying the potential relationship between the inhibition function and the ability of making decisions (see also Sakagami et al., 2006). In our opinion, the impact of anxiety on inhibition control might account for highanxiety people's risk-avoidance tendency.

Below we would introduce a study that focuses on the potential influence of inhibition function on high-anxiety people's decision-making strategies. A version of Gehring \& Willoughby (2002) monetary gambling task was applied while the subjects were under electroencephalogram (EEG) recording. The ERP component P3 was chosen for analysis, for its significance to ERP research on decision making (Christie \& Tata, 2009; P. Li et al., 2010; Polezzi, Sartori, Rumiati, Vidotto, \& Daum, 2010; Wu \& Zhou, 2009). The P3 component is a centro-parietal positivity approximately $300-600$ ms post-stimulus. In the area of decisionmaking research, enhanced P3 has been linked to motivationally salient and rewarding outcomes (Bellebaum \& Daum, 2008; Hajcak, Moser, Holroyd, \& Simons, 2007; Martin \& Potts, 2004a). The relationship between P3 amplitude and decision-making behavior has been implicated in clinical studies, such as research on alcoholics (Maurage et al., 2007) and impulsive individuals (Martin \& Potts, 2004b).

In this study, 253 undergraduate students (all Chinese) participated in a mass screening with the Chinese version of Spielberger's trait anxiety (STAI-T) inventory. This scale has demonstrated good internal consistency, as well as convergent and discriminant validity (Shek, 1993; Spielberger et al., 1983). Subsequently, students who scored high in trait anxiety (in the upper $25 \%$ of the distribution) were considered as high-trait anxiety people, while the students who scored low (in the lower $25 \%$ of the distribution) were considered as lowtrait anxiety (LTA) people. From those who fit these criteria, we randomly chose 41 students and invited them to participate in the experiment. 20 of them were assigned to the high-trait anxiety (HTA) group ( 8 females), while 21 were assigned to the low-trait anxiety (LTA) group (10 females). An independent-samples t-test revealed that the two groups differed significantly in trait anxiety score, but not in age.

During each trial of the formal task, the subjects were asked to select one of the two alternative options. One of the option was presented as number ' 9 ' and the other was ' 99 ', indicating the amount of score that was potentially linked with the subjects' choice. After the decision was made, the result of the subject's choice was presented on the screen. There were four kinds of outcome valence: positive $\left({ }^{\prime}+{ }^{\prime}\right)$, negative $\left({ }^{\prime}-{ }^{\prime}\right)$, neutral $\left({ }^{\prime} 0{ }^{\prime}\right)$, and ambiguous $\left({ }^{\prime{ }^{\prime} \prime}\right)$. The positive outcome indicated that the subject won as many points as he/she chose in this trial, while the negative outcome indicated the reverse. The neutral outcome meant the subject neither won nor lost. The ambiguous outcome was uninformative, of which the valence could be positive, negative or neutral. Unbeknownst to the subject, the outcomes were provided according to a pre-determined pseudorandom sequence, and all subjects received exactly 160 of each kind of 
outcome. At the end of the task, the subject was informed of the total score that he/she had earned. Then they were paid 60-80 Chinese Yuan for their participation (the exact number was depended on task performance).

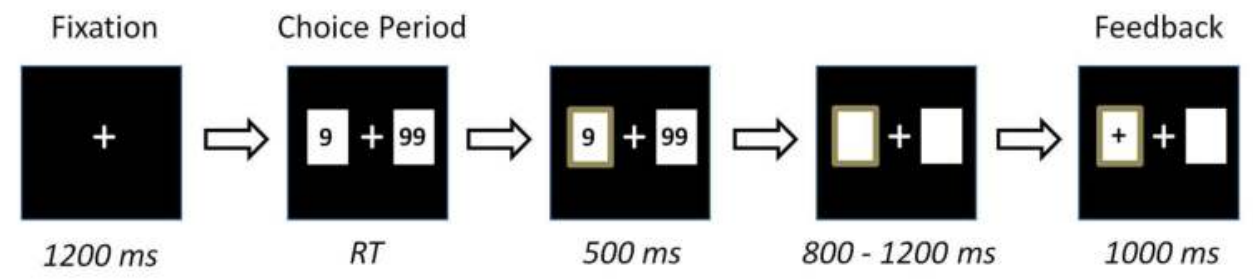

Fig. 1. The sequence of events within a single trial of the monetary gambling task, applied in the experiment.

We defined the choice of ' 9 ' to be the risk-avoidant choice (low-risk \& low return) in our experiment, predicting that subjects would make this choice to avoid the possibility of a large loss ('-99'). However, by making this choice, they also gave up the opportunity to receive the larger reward $\left({ }^{\prime}+99^{\prime}\right)$. In contrast, the choice of ' $99^{\prime}$ was defined as the risky choice (high-risk \& high-return). Correspondingly, the outcomes following risk-avoidant choices were defined as 'small outcomes', while the outcomes following risky choices were defined as 'large outcomes'.

For the purpose of investigating the potential influence of different kinds of outcome on ongoing decision-making, we calculated the ratio of risk-avoidant choice associated with each kind of outcome. To accomplish this, we divided the number of risk-avoidant choices following each kind of outcome by the total number of choices following the corresponding outcome. The results are described below as 'risk-avoidant ratio'. Please note that it is not necessary to calculate the 'risky ratio', since 'risky ratio' would be equal to 1 minus 'riskavoidant ratio'.

The P3 amplitude was measured base-to-peak as the most positive value within a 300-600 ms window. The data were derived from all electrodes. However, only the electrodes at which the component reached its maximum were entered into analysis. According to the observation on scalp topography, the amplitude of P3 was maximal at centro-parietal areas of the scalp, at electrode position $\mathrm{CPz}$. Accordingly, the $\mathrm{P} 3$ peak amplitude of electrode $\mathrm{CPz}$, as well as 8 adjacent electrodes $(\mathrm{C} 1, \mathrm{Cz}, \mathrm{C} 2, \mathrm{CP} 1, \mathrm{CP} 2, \mathrm{P} 1, \mathrm{Pz}, \mathrm{P} 2)$, were chosen to enter into analysis.

A repeated-measure ANOVA was used with anxiety level (high/low), outcome valence (positive/negative/neutral/ambiguous), outcome magnitude (9/99, or small/large), and electrode ( 9 sites) as statistical factors. The Greenhouse-Geisser epsilon correction was applied to adjust the degrees of freedom of the F-ratios when necessary. A two-tailed Pearson correlation was calculated between risk-avoidant ratios following each kind of outcome, and the P3 amplitude following the corresponding outcome. Interestingly, we found some part of the correlation results of the P3 amplitude were significant (see Table 1). When the outcome magnitude was small, the correlations between risk-avoidant ratio and P3 amplitude reached significance only when the outcome valence was neutral. In comparison, following a large outcome, the correlations between risk-avoidant ratio and P3 
amplitude were significant, regardless of the outcome valence. These correlations were positive, indicating the relationship between P3 amplitude and individual difference in decision-making strategy was that the subjects, who showed larger P3 in response to larger outcomes, were more likely to be risk-avoidant (after receiving these kinds of outcomes) compared to those who showed smaller P3 responses.

In order to examine the potential effect of anxiety, the two-tailed Pearson correlation between risk-avoidant ratio and P3 amplitude was calculated in HTA group and LTA group independently. The results were also presented in Table 1. We suggest these results implied that the correlation between risk-avoidant ratio and P3 response was stronger in HTA group than in LTA group. In HTA group, when participants received a large outcome, the correlations between P3 amplitude and risk-avoidant ratio were significant regardless of the outcome valence. However in LTA group, the correlation was significant only when the outcome valence was 'ambiguous'.

\begin{tabular}{|c|c|c|c|c|}
\hline \multirow{4}{*}{} & \multicolumn{4}{|c|}{ outcomes following risky choice (large outcome) } \\
\cline { 2 - 5 } & positive(+) & negative(-) & neutral $(0)$ & ambiguous(*) \\
\hline \multirow{2}{*}{ Total } & $\begin{array}{c}r=0.460 \\
(p=0.004)\end{array}$ & $\begin{array}{c}r=0.447 \\
(p=0.005)\end{array}$ & $\begin{array}{c}r=0.482 \\
(p=0.002)\end{array}$ & $\begin{array}{c}r=0.568 \\
(p<0.001)\end{array}$ \\
\hline \multirow{2}{*}{ HTA } & $\begin{array}{c}r=0.695 \\
(p=0.001)\end{array}$ & $\begin{array}{c}r=0.516 \\
(p=0.028)\end{array}$ & $\begin{array}{c}r=0.628 \\
(p=0.005)\end{array}$ & $\begin{array}{c}r=0.709 \\
(p=0.001)\end{array}$ \\
\hline \multirow{2}{*}{ LTA } & $\begin{array}{c}r=0.271 \\
(p=0.248)\end{array}$ & $\begin{array}{c}r=0.419 \\
(p=0.066)\end{array}$ & $\begin{array}{c}r=0.383 \\
(p=0.096)\end{array}$ & $\begin{array}{c}r=0.462 \\
(p=0.040)\end{array}$ \\
\hline
\end{tabular}

Table 1. The two-tailed Pearson correlations between risk-avoidant ratio and the amplitude of P3 associated with different kind of outcomes, in the entire sample (first line), in HTA group (second line), and in LTA group (third line). The amplitude of P3 used to calculate correlation was the mean of the records at 9 sites $(\mathrm{C} 1, \mathrm{Cz}, \mathrm{C} 2, \mathrm{CP} 1, \mathrm{CPz}, \mathrm{CP} 2, \mathrm{P} 1, \mathrm{Pz}$ and P2). The $p$ values are given below the corresponding correlation values. The significant results are highlighted in red.

In this study, the 'risk-avoidant ratio' and the P3 amplitude following large outcomes were positively correlated. These results indicated that the subjects, who showed larger P3 after 
receiving large outcomes, were more likely to make risk-avoidant choice following such outcomes. In other words, the amplitude of P3 in response to large outcomes served as an indicator of individual decision-making strategy. Presumably, the motivational significance of small outcomes is not strong enough to produce individual difference in outcome evaluation (for the relationship between the P3 amplitude and motivational significance, see Nieuwenhuis, Aston-Jones, \& Cohen, 2005). Thus, most of the correlations between riskavoidant ratio and P3 following small outcomes did not reach significance.

Our results suggest that the correlations between P3 amplitude and decision-making strategy might be mediated by individual difference in personalities. In particular, these correlations are likely to be influenced by levels of anxiety. Among the high-anxiety people, the correlation between P3 amplitude and risk-avoidant ratio was stronger. This phenomenon is linked with the opinion that there is a relationship between anxiety and risk-avoidant inclination (Eisenberg et al., 1998; Raghunathan \& Pham, 1999). However, our results suggest that this relationship might be indirect, since the main effect of anxiety on behavior data or the P3 amplitude did not reach significance. Accordingly, we suggest the risk-avoidant tendency might be determined by the interaction between anxiety and other kinds of personalities (e.g., sensitivity for punishment and reward. See Franken \& Muris, 2005).

Aside from anxiety, previous studies have reported that the impulsive individuals, who manifest pathological gambling behavior, show smaller P3 than control subjects (Martin \& Potts, 2004a), which is consistent with the pattern of our results. Future research measuring individual differences in personality traits related to risky behavior (e.g. impulsivity and reward-seeking) will elucidate the problem (see Hsee \& Hastie, 2006).

According to some researchers, the P3 amplitude is a reflection of inhibitory activity level (Sanz, Molina, Martin-Loeches, Calcedo, \& Rubia, 2001). The frontal lobe is directly related to this inhibitory process, while many authors have emphasized the participation of the frontal lobe in P3 generation (Alexander, DeLong, \& Strick, 1986; Savage et al., 1994). In our opinion, the relationship between the P3 component and risk-avoidant tendency in this study might imply the impact of inhibition function on decision making. That is, the P3 amplitude reflects the subject's effort to inhibit his/her desire to search for high-return benefit. It is not surprising that this relationship is more prominent in the HTA group, since high-anxiety people are more willing to avoid potential risk. Therefore, they are more likely to successfully inhibit the impulse to make a risk-seeking decision, indicated by the higher correlation between P3 amplitude and risk-avoidant ratio.

We suggest that our results provide new insight into the relationship between anxiety level, inhibition function, and decision making. High-anxiety people are more prone to make riskavoidant choices, because the activity of inhibition control impacts their decision-making behavior more strongly, compared to low-anxiety people. To take a step further, we argue that our discovery is not limited in the area of economic decision making. Anxiety urges us to make conservative decision in the same way that it protects us from potential threats (see Maner et al., 2007).

Interestingly, the overall risk-avoidant ratio was not sensitive to the level of anxiety in this study, which might be inconsistent with the results of previous research (Eisenberg et al., 1998; Miu et al., 2008; Raghunathan \& Pham, 1999; Shepperd et al., 2005). It might be worth pointing out that in previous studies, the subjects' decision-making tendencies were investigated with questionnaires, and no feedback would be expected in this kind of experiment (i.e. Eisenberg et al., 1998). In contrast, participants would immediately receive 
the outcome associated with their choice after a decision had been made in our task. We suggest that throughout our task, the participants always adjusted their decision-making strategies according to the outcomes they got. That is to say, the task is actually a process of probability learning for the participants. Therefore, it is not surprising that the influence of anxiety on overall behavioral performance was not significant. According to this theory, when the outcome is not available in each trial, the impact of anxiety on decision-making tendency should be stronger. This hypothesis is supported by one of our recent studies, in which the 'framing effect' paradigm was applied and no outcome was provided after the participants made their decision. In that study, we confirm that high-anxiety people chose the risk-avoidant option more often than low-anxiety people.

To sum up, in the current study, high-anxiety and low-anxiety participants did not significantly differ in their decision-making tendency. Nevertheless, anxiety impacted decision-making behavior in an indirect way. The P3 amplitude elicited by the outcome was significantly correlated with the risk-avoidant ratio, while this phenomenon was more prominent in the high-anxiety group than the low-anxiety group. In our opinion, the relationship between P3 amplitude and risk-avoidant ratio reflects the role of inhibition function in decision making. This relationship is stronger among high-anxiety people, because they are more likely to inhibit their desire to choose high-risk/high-return option. The results of this study extend our understanding about the impact of high-anxiety people's inhibition function on their behavior.

\section{Conclusion}

This chapter provides a review of two of our recent studies, which are interested in the relationship between anxiety and inhibition function. Although they focus on different aspects of human behavior (emotional processing and economic decision making, respectively), both of them indicate the importance of inhibition function to high-anxiety people's behavior. According to the ERP results, in the emotional processing study, lowanxiety subjects selectively inhibited the processing of negative stimuli, while high-anxiety subjects treated positive and negative stimuli equally. In the decision making study, there existed a relationship between risk-avoidant tendency and the subjects' effort to inhibit their impulse to choose high-risk/high-return option. Both findings imply that high-anxiety people might exhibit some degree of excessive inhibition (Huang et al., 2009), which is inconsistent with some previous research (i.e. Derakshan et al., 2009; Mayer \& Merckelbach, 1999; Sanz et al., 2001). Further investigation would be necessary to verify whether highanxiety people's inhibition function is hypoactive or hyperactive, compared to low-anxiety people. In our opinion, both of the hypotheses might be true. Strong anxious feeling interferes with the activity of the brain regions that are associated with the inhibition function, such as prefrontal cortex (Bishop, 2007; Bishop et al., 2004). Therefore, the highanxiety peoples' inhibition function might act abnormally in the way that either a hypoactive or a hyperactive state would appear, depending on the circumstance. Future research on this issue will prove beneficial to both clinical and non-clinical studies.

In both of our studies, the impact of the inhibition function is indexed by the amplitude of ERP P3 component. Inspired by some previous research (i.e. Falkenstein et al., 1999; Righi, Mecacci, \& Viggiano, 2009; Sanz et al., 2001), we associate P3 amplitude and the inhibition 
function in our research. In other studies, the P3 (including so-call 'P3a' and 'P3b') is also suggested to be linked with different types of cognitive abilities, such as working memory updating (Donchin \& Coles, 1988), allocation of processing resources (Imai \& Tsuji, 2004; Utku, Erzengin, Cakmak, \& Karakas, 2002), perceptual awareness (Hon, Epstein, Owen, \& Duncan, 2006), sensory discrimination (Molnar, 1999), revision of the mental representation (Pontifex, Hillman, \& Polich, 2009), or cognitive self-evaluation (Righi et al., 2009). It would be worthwhile to see if the P3 actually reflects the activity of a fundamental cognitive component of these abilities. In addition, P3 amplitude reduction has long been associated with various kinds of problem behaviors, e.g., alcoholism (Maurage et al., 2007), drug abuse (Iacono \& Mcgue, 2006), obsessive-compulsive disorder (Sanz et al., 2001), and pathological gambling (Stojanov et al., 2003). In the near future, we might see the P3 be regarded as a supplemental diagnostic indicator in the area of clinical psychology, like the case of P50 in schizophrenia (de Wilde, Bour, Dingemans, Koelman, \& Linszen, 2007; Kurayama et al., 2009; Sanchez-Morla et al., 2008).

\section{Acknowledgement}

This work was supported by Ministry of Sci \& Tech (973 Program, 2011CB711000), the National Natural Science Foundation of China (30930031, 30800298), National Key Technologies R\&D Program (2009BAI77B01), Global Research Initiative Program, and United States National Institute of Health grants (1R01TW007897, P50DA05312). The authors thank the writing center in the University of Kentucky for help with language editing.

\section{Reference}

Alexander, G. E., DeLong, M. R., \& Strick, P. L. (1986). Parallel organization of functionally segregated circuits linking basal ganglia and cortex. Annu Rev Neurosci, 9, 357-381.

Aron, A. R., Fletcher, P. C., Bullmore, E. T., Sahakian, B. J., \& Robbins, T. W. (2003). Stopsignal inhibition disrupted by damage to right inferior frontal gyrus in humans. Nature Neuroscience, 6(2), 115-116.

Bai, L., Ma, H., Huang, Y. X., \& Luo, Y. J. (2005). The development of native chinese affective picture system - a pretest in 46 college students. Chinese Journal of Mental Health, 19, 719-722.

Bar-Haim, Y., Lamy, D., \& Glickman, S. (2005). Attentional bias in anxiety: A behavioral and ERP study. Brain and Cognition, 59(1), 11-22.

Barkley, R. A. (1997). Behavioral inhibition, sustained attention, and executive functions: Constructing a unifying theory of ADHD. Psychological Bulletin, 121(1), 65-94.

Bellebaum, C., \& Daum, I. (2008). Learning-related changes in reward expectancy are reflected in the feedback-related negativity. European Journal of Neuroscience, 27(7), 1823-1835.

Bishop, S. J. (2007). Neurocognitive mechanisms of anxiety: an integrative account. Trends in Cognitive Sciences, 11(7), 307-316.

Bishop, S. J. (2009). Trait anxiety and impoverished prefrontal control of attention. Nature Neuroscience, 12(1), 92-98. 
Bishop, S. J., Duncan, J., \& Lawrence, A. D. (2004). Prefrontal cortical function and anxiety: controlling attention to threat-related stimuli. Nature Neuroscience, 7(2), 184-188.

Christie, G. J., \& Tata, M. S. (2009). Right frontal cortex generates reward-related theta-band oscillatory activity. Neuroimage, 48(2), 415-422.

Critchley, H. D., Mathias, C. T., \& Dolan, R. J. (2001). Neuroanatomical basis for first- and second-order representations of bodily states. Nature Neuroscience, 4(2), 207-212.

Crowne, D. P., \& Marlowe, D. (1960). A new scale of social desirability independent of psychopathology. J Consult Psychol, 24, 349-354.

De Martino, B., Kumaran, D., Seymour, B., \& Dolan, R. J. (2006). Frames, biases, and rational decision-making in the human brain. Science, 313(5787), 684-687.

de Wilde, O. M., Bour, L. J., Dingemans, P. M., Koelman, J. H., \& Linszen, D. H. (2007). A meta-analysis of P50 studies in patients with schizophrenia and relatives: differences in methodology between research groups. Schizophr Res, 97(1-3), 137151.

Derakshan, N., Ansari, T. L., Hansard, M., Shoker, L., \& Eysenck, M. W. (2009). Anxiety, Inhibition, Efficiency, and Effectiveness An Investigation Using the Antisaccade Task. Experimental Psychology, 56(1), 48-55.

Dias, R., Robbins, T. W., \& Roberts, A. C. (1997). Dissociable forms of inhibitory control within prefrontal cortex with an analog of the Wisconsin Card Sort Test: Restriction to novel situations and independence from "on-line" processing. Journal of Neuroscience, 17(23), 9285-9297.

Donchin, E., \& Coles, M. G. H. (1988). Is the P300 component a manifestation of context updating? . Behavioral and Bran Sciences, 11(3), 355-372.

Eisenberg, A. E., Baron, J., \& Seligman, M. E. P. (1998). Individual difference in risk aversion and anxiety. Psychological Bulletin, 87, 245-251.

Enright, S. J., \& Beech, A. R. (1993). Reduced cognitive inhibition in obsessive-compulsive disorder. Br J Clin Psychol, 32 ( Pt 1), 67-74.

Etkin, A., Klemenhagen, K., \& Dudmen, J. T. (2004). Individual difference in trait anxiety predict the response of the basolateral amygdala to unconsciously processed fearful faces. Neuron, 44, 1043-1055.

Eysenck, M. W., Derakshan, N., Santos, R., \& Calvo, M. G. (2007). Anxiety and cognitive performance: attentional control theory. Emotion, 7(2), 336-353.

Falkenstein, M., Hoormann, J., \& Hohnsbein, J. (1999). ERP components in Go Nogo tasks and their relation to inhibition. Acta Psychologica, 101(2-3), 267-291.

Fallgatter, A. J., Bartsch, A. J., \& Herrmann, M. J. (2002). Electrophysiological measurements of anterior cingulate function. Journal of Neural Transmission, 109(5-6), 977-988.

Fichtenholtz, H. M., Dean, H. L., Dillon, D. G., Yamasaki, H., McCarthy, G., \& LaBar, K. S. (2004). Emotion-attention network interactions during a visual oddball task. Cognitive Brain Research, 20(1), 67-80.

Franken, I. H. A., \& Muris, P. (2005). Individual differences in reward sensitivity are related to food craving and relative body weight in healthy women. Appetite, 45(2), 198201.

Funahashi, S. (2001). Neuronal mechanisms of executive control by the prefrontal cortex. Neurosci Res, 39(2), 147-165.

Gehring, W. J., \& Willoughby, A. R. (2002). The medial frontal cortex and the rapid processing of monetary gains and losses. Science, 295(5563), 2279-2282. 
Geurts, H. M., van der Oord, S., \& Crone, E. A. (2006). Hot and cool aspects of cognitive control in children with ADHD: decision-making and inhibition. J Abnorm Child Psychol, 34(6), 813-824.

Goel, V., \& Dolan, R. J. (2000). Anatomical segregation of component processes in an inductive inference task. Journal of Cognitive Neuroscience, 12(1), 110-119.

Goyer, J. P., Woldorff, M. G., \& Huettel, S. A. (2008). Rapid Electrophysiological Brain Responses are Influenced by Both Valence and Magnitude of Monetary Rewards. Journal of Cognitive Neuroscience, 20(11), 2058-2069.

Hajcak, G., Moser, J. S., Holroyd, C. B., \& Simons, R. F. (2007). It's worse than you thought: The feedback negativity and violations of reward prediction in gambling tasks. Psychophysiology, 44(6), 905-912.

Hon, N., Epstein, R. A., Owen, A. M., \& Duncan, J. (2006). Frontoparietal activity with minimal decision and control. Journal of Neuroscience, 26(38), 9805-9809.

Hsee, C. K., \& Hastie, R. (2006). Decision and experience: why don't we choose what makes us happy? Trends in Cognitive Sciences, 10(1), 31-37.

Huang, Y. X., Bai, L., Ai, H., Li, W., Yua, C., Liu, J., et al. (2009). Influence of trait-anxiety on inhibition function: Evidence from ERPs study. Neuroscience Letters, 456(1), 1-5.

Iacono, W. G., \& Mcgue, M. (2006). Association between P3 event-related brain potential amplitude and adolescent problem behavior. Psychophysiology, 43(5), 465-469.

Ilan, A. B., \& Polich, J. (1999). P300 and response time from a manual Stroop task. Clinical Neurophysiology, 110(2), 367-373.

Imai, A., \& Tsuji, K. (2004). Event-related potential correlates of judgment categories and detection sensitivity in a visual detection task. Vision Research, 44(8), 763-773.

Kurayama, T., Nakazawa, K., Matsuzawa, D., Yoshida, S., Nanbu, M., Suto, C., et al. (2009). Alterations of Auditory P50 Suppression in Human Fear Conditioning and Extinction. Biological Psychiatry, 65(6), 495-502.

Li, C. S. R., Kosten, T. R., \& Sinha, R. (2005). Sex differences in brain activation during stress imagery in abstinent cocaine users: A functional magnetic resonance imaging study. Biological Psychiatry, 57(5), 487-494.

Li, P., Jia, S. W., Feng, T. Y., Liu, Q. A., Suo, T., \& Li, H. (2010). The influence of the diffusion of responsibility effect on outcome evaluations: Electrophysiological evidence from an ERP study. Neuroimage, 52(4), 1727-1733.

Li, X. Y., Wang, M., Poltakoff, E., \& Luo, Y. J. (2007). Attention to threat in high and low trait-anxious individuals: A study using extremely threatening pictorial cues. Perceptual and Motor Skills, 104(3), 1097-1106.

Livesley, W. J., Jang, K. L., \& Vernon, P. A. (1998). Phenotypic and genetic structure of traits delineating personality disorder. Archives of General Psychiatry, 55(10), 941-948.

Lust, S. A., \& Bartholow, B. D. (2009). Self-reported and P3 event-related potential evaluations of condoms: Does what we say match how we feel? Psychophysiology, $46(2), 420-424$.

Maner, J. K., Richey, J. A., Cromer, K., Mallott, M., Lejuez, C. W., Joiner, T. E., et al. (2007). Dispositional anxiety and risk-avoidant decision-making. Personality and Individual Differences, 42(4), 665-675.

Maner, J. K., \& Schmidt, N. B. (2006). The role of risk avoidance in anxiety. Behavior Therapy, 37(2), 181-189. 
Martin, L. E., \& Potts, G. F. (2004a). Impulsivity and decision-making: An event related potential investigation. Psychophysiology, 41, S66-S66.

Martin, L. E., \& Potts, G. F. (2004b). Reward sensitivity in impulsivity. Neuroreport, 15(9), 1519-1522.

Maurage, P., Philippot, P., Verbanck, P., Noel, X., Kornreich, C., Hanak, C., et al. (2007). Is the P300 deficit in alcoholism associated with early visual impairments (P100, N170)? An oddball paradigm. Clinical Neurophysiology, 118(3), 633-644.

Mayer, B., \& Merckelbach, H. (1999). Unconscious processes, subliminal stimulation, and anxiety. Clin Psychol Rev, 19(5), 571-590.

McClure, S. M., Laibson, D. I., Loewenstein, G., \& Cohen, J. D. (2004). Separate neural systems value immediate and delayed monetary rewards. Science, 306(5695), 503507.

McNaughton, N. (1997). Cognitive dysfunction resulting from hippocampal hyperactivity--a possible cause of anxiety disorder? Pharmacol Biochem Behav, 56(4), 603-611.

McNaughton, N. (2006). The role of the subiculum within the behavioural inhibition system. Behav Brain Res, 174(2), 232-250.

McNaughton, N., \& Gray, J. A. (2000). Anxiolytic action on the behavioural inhibition system implies multiple types of arousal contribute to anxiety. Journal of Affective Disorders, 61(3), 161-176.

Miu, A. C., Heilman, R. M., \& Houser, D. (2008). Anxiety impairs decision-making: Psychophysiological evidence from an Iowa Gambling Task. Biological Psychology, 77(3), 353-358.

Mogg, K., \& Bradley, B. P. (1998). A cognitive-motivational analysis of anxiety. Behav Res Ther, 36(9), 809-848.

Mogg, K., Bradley, B. P., Williams, R., \& Mathews, A. (1993). Subliminal processing of emotional information in anxiety and depression. J Abnorm Psychol, 102(2), 304-311.

Molnar, M. (1999). The dimensional complexity of the P3 event-related potential: areaspecific and task-dependent features. Clinical Neurophysiology, 110(1), 31-38.

Moser, J. S., Hajcak, G., Bukay, E., \& Simons, R. F. (2006). Intentional modulation of emotional responding to unpleasant pictures: An ERP study. Psychophysiology, 43(3), 292-296.

Nieuwenhuis, S., Aston-Jones, G., \& Cohen, J. D. (2005). Decision making, the p3, and the locus coeruleus-norepinephrine system. Psychological Bulletin, 131(4), 510-532.

Nigg, J. T. (2000). On inhibition/disinhibition in developmental psychopathology: views from cognitive and personality psychology and a working inhibition taxonomy. Psychol Bull, 126(2), 220-246.

Nigg, J. T. (2001). Is ADHD a disinhibitory disorder? Psychological Bulletin, 127(5), 571-598.

Noel, X., Bechara, A., Dan, B., Hanak, C., \& Verbanck, P. (2007). Response inhibition deficit is involved in poor decision making under risk in nonamnesic individuals with alcoholism. Neuropsychology, 21(6), 778-786.

Polezzi, D., Sartori, G., Rumiati, R., Vidotto, G., \& Daum, I. (2010). Brain correlates of risky decision-making. Neuroimage, 49(2), 1886-1894.

Pontifex, M. B., Hillman, C. H., \& Polich, J. (2009). Age, physical fitness, and attention: P3a and P3b. Psychophysiology, 46(2), 379-387. 
Raghunathan, R., \& Pham, M. T. (1999). All Negative Moods Are Not Equal: Motivational Influences of Anxiety and Sadness on Decision Making. Organizational Behavior and Human Decision Processes, 79(1), 56-77.

Reidy, J., \& Richards, A. (1997). Anxiety and memory: a recall bias for threatening words in high anxiety. Behav Res Ther, 35(6), 531-542.

Righi, S., Mecacci, L., \& Viggiano, M. P. (2009). Anxiety, cognitive self-evaluation and performance: ERP correlates. Journal of Anxiety Disorders, 23(8), 1132-1138.

Roiser, J. P., de Martino, B., Tan, G. C. Y., Kumaran, D., Seymour, B., Wood, N. W., et al. (2009). A Genetically Mediated Bias in Decision Making Driven by Failure of Amygdala Control. Journal of Neuroscience, 29(18), 5985-5991.

Rushworth, M. F. S., \& Behrens, T. E. J. (2008). Choice, uncertainty and value in prefrontal and cingulate cortex. Nature Neuroscience, 11(4), 389-397.

Sakagami, M., Pan, X. C., \& Uttl, B. (2006). Behavioral inhibition and prefrontal cortex in decision-making. Neural Networks, 19(8), 1255-1265.

Sanchez-Morla, E. M., Garcia-Jimenez, M. A., Barabash, A., Martinez-Vizcaino, V., Mena, J., Cabranes-Diaz, J. A., et al. (2008). P50 sensory gating deficit is a common marker of vulnerability to bipolar disorder and schizophrenia. Acta Psychiatr Scand, 117(4), 313-318.

Sanz, M., Molina, V., Martin-Loeches, M., Calcedo, A., \& Rubia, F. J. (2001). Auditory P300 event related potential acid serotonin reuptake inhibitor treatment in obsessivecompulsive disorder patients. Psychiatry Research, 101(1), 75-81.

Savage, C. R., Weilburg, J. B., Duffy, F. H., Baer, L., Shera, D. M., \& Jenike, M. A. (1994). Low-level sensory processing in obsessive-compulsive disorder: an evoked potential study. Biol Psychiatry, 35(4), 247-252.

Shek, D. T. (1993). The Chinese version of the State-Trait Anxiety Inventory: its relationship to different measures of psychological well-being. J Clin Psychol, 49(3), 349-358.

Shepperd, J. A., Grace, J., Cole, L. J., \& Klein, C. (2005). Anxiety and outcome predictions. Personality and Social Psychology Bulletin, 31(2), 267-275.

Spielberger, C. D., Gorsuch, R. L., Lushene, R., Vagg, P. R., \& Jacobs, G. A. (1983). Manual for the state-trait anxiety inventory. Palo Alto, CA: Consulting Psychologist Press.

Stojanov, W., Karayanidis, F., Johnston, P., Bailey, A., Carr, V., \& Schall, U. (2003). Disrupted sensory gating in pathological gambling. Biological Psychiatry, 54(4), 474-484.

Utku, H., Erzengin, O. U., Cakmak, E. D., \& Karakas, S. (2002). Discrimination of brain's neuroelectric responses by a decision-making function. J Neurosci Methods, 114(1), 25-31.

Wang, X. D., Wang, X. L., \& Ma, H. (1999). Rating Scales for Mental Health. Beijing: Chinese Mental HealthPress.

Wray, L. D., \& Stone, E. R. (2005). The role of self-esteem and anxiety in decision making for self versus others in relationships. Journal of Behavioral Decision Making, 18(2), 125144.

Wu, Y., \& Zhou, X. L. (2009). The P300 and reward valence, magnitude, and expectancy in outcome evaluation. Brain Research, 1286, 114-122.

Yamasaki, H., LaBar, K. S., \& McCarthy, G. (2002). Dissociable prefrontal brain systems for attention and emotion. Proc Natl Acad Sci U S A, 99(17), 11447-11451. 
Yee, P. L., \& Vaughan, J. (1996). Intergrating cognitive, personality, and social approaches to cognitive interference and distractibility. In G. R. Pierce, B. R. Sarason \& I. G. Sarason (Eds.), Cognitive Interference: Theories, Methods, and Findings (pp. 77-98). Mahwah, NJ: Lawrence Erlbaum Associates.

Zheng, X. H., Shu, L., Zhang, A. L., Huang, G. L., Zhao, J. F., Sun, M., et al. (1993). Test of State-Trait Anxiety Inventory in Changchun. Chinese Journal of Mental Health, 7(2), 60-62. 


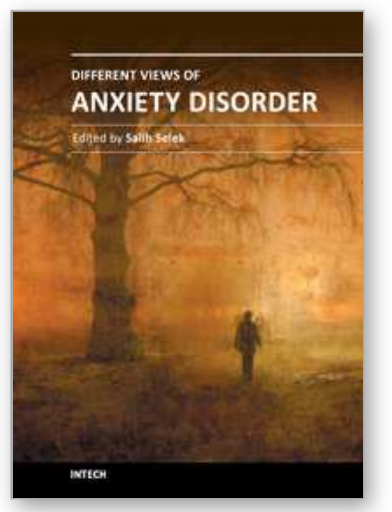

\author{
Different Views of Anxiety Disorders \\ Edited by Dr. Salih Selek
}

ISBN 978-953-307-560-0

Hard cover, 370 pages

Publisher InTech

Published online 12, September, 2011

Published in print edition September, 2011

Anxiety, whether an illness or emotion, is a term with historical roots even in the Bible, but it was not popular until the modern age. Today, we can group, diagnose and treat several anxiety disorders to an extent, but the assessment of symptoms and severity, dealing with resistant conditions, new treatment modalities and specific patient population, such as children, are still the challenging aspects of anxiety disorders. This book intends to present anxiety disorders from a different view and discuss a wide variety of topics in anxiety from a multidimensional approach. This Open Access book addresses not only psychiatrists but also a broad range of specialists, including psychologists, neuroscientists and other mental health professionals.

\title{
How to reference
}

In order to correctly reference this scholarly work, feel free to copy and paste the following:

Yue-jia Luo, Ruolei Gu and Yu-xia Huang (2011). Influence of Trait-Anxiety on Inhibition Function: Evidence from ERP Studies, Different Views of Anxiety Disorders, Dr. Salih Selek (Ed.), ISBN: 978-953-307-560-0, InTech, Available from: http://www.intechopen.com/books/different-views-of-anxiety-disorders/influence-oftrait-anxiety-on-inhibition-function-evidence-from-erp-studies

\section{INTECH}

open science | open minds

\section{InTech Europe}

University Campus STeP Ri Slavka Krautzeka 83/A 51000 Rijeka, Croatia Phone: +385 (51) 770447

Fax: +385 (51) 686166 www.intechopen.com

\section{InTech China}

Unit 405, Office Block, Hotel Equatorial Shanghai No.65, Yan An Road (West), Shanghai, 200040, China 中国上海市延安西路65号上海国际贵都大饭店办公楼 405 单元 Phone: +86-21-62489820

Fax: $+86-21-62489821$ 
(C) 2011 The Author(s). Licensee IntechOpen. This chapter is distributed under the terms of the Creative Commons Attribution-NonCommercialShareAlike-3.0 License, which permits use, distribution and reproduction for non-commercial purposes, provided the original is properly cited and derivative works building on this content are distributed under the same license. 